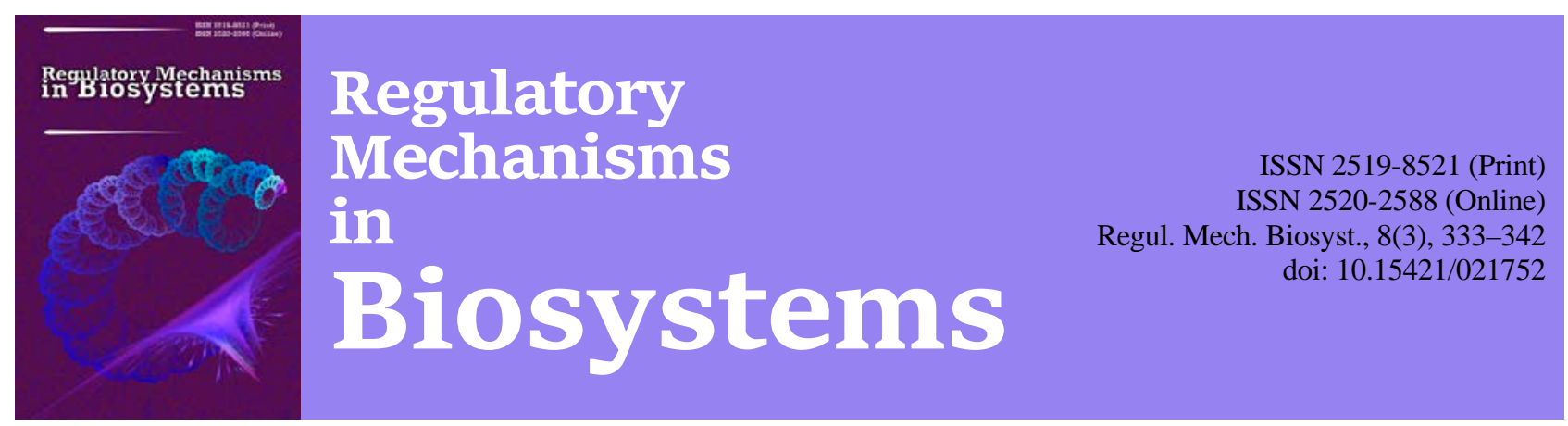

\title{
Features of structure of motor nerve endings in the tongue of normal and dehydrated rats
}

\author{
S. L. Popel’*, O. T. Bylous**, I. V. Bylous* \\ *Vasyl Stefanik Precarpatian National University, Ivano-Frankivsk, Ukraine \\ **Ivano-Frankivsk National Medical University, Ivano-Frankivsk, Ukraine
}

Article info

Received 12.06.2017

Received in revised form 16.07.2017

Accepted 20.07.2017

Vasyl Stefanik Precarpatian

National University,

Shevchenko Str., 57,

Ivano-Frankivsk, 76018, Ukraine.

Ivano-Frankivsk National

Medical University,

Galitcka Str., 2,

Ivano-Frankivsk, 76025, Ukraine.

Tel.: +38-097-87-41-446.

E-mail:popelsergij@gmail.com
Popel', S. L., Bylous, O. T., \& Bylous, I. V. (2017). Features of structure of motor nerve endings in the tongue of normal and dehydrated rats. Regulatory Mechanisms in Biosystems, 8(3), 333-342. doi: 10.15421/021752

This study aims at an analytical review of scientific literature on the structure of the tongue of different animals and humans, and also at studying the features of the structure of motor nerve endings in the tongue muscles of healthy rats and rats that have undergone prolonged dehydration. Over 14 days, using histological methods we studied neuromuscular endings and peculiarities of their distribution in the tongue muscles of 25 mature rats, both in normal condition and under dehydration. The analysis of the results showed different structures of differentiated motor nerve endings among the rats in normal condition, and also revealed the peculiarities and quantitative characteristics of the components of the neuromuscular endings in relation to the duration of dehydration. The type of neuromuscular ending reflects the morphologically interdependent structure of efferent neuromediators in relation to a part of the tongue. This may determine the nature of the processes of prehension and chewing of food. The structure of neuromuscular endings of the muscles of the tip of the tongue is the most differentiated, they are more numerous and larger. The tip of the tongue of rats had a higher number of nuclei and larger size of the neuromuscular endings of the muscles than the other parts. This, perhaps, is determined by the speed of the movements of the tongue due to eating different foods. The number of nuclei and the size of neuromuscular endings are characterized by significant variations in the pattern of axon branching, which is determined by the anatomical, physiological and biomechanical conditions of functioning of the rats' tongue muscles. The quantitative analysis of structural peculiarities of axomycin synapses showed that muscle fibers of the tongue have neuroumuscular endings with regulated synaptoarchitectonics which is characterized by the sprouting of the motor axon, a certain length and width of the active zones, number and size of the synaptic folds, number of terminal neurolemmocytes, and the peculiarity in structure of the subsynaptic area. Muscle fibers in the body of the tongue have the most complex special distribution of presynaptic pole of axomuscular synapses, they also have the highest number of active zones and synaptic folds. We determined the main reactive and destructive processes while distinguishing certain phases of morphologically-functional changes in the organism under total dehydration. A complex analysis of the morpho-functional characteristics of the peripheral nervous apparatus of the tongue of rats subject to total dehydration helped reveal the structural rearrangement of the neuromuscular endings over certain periods. During first three days after the beginning of the dehydration modeling, a structural adaptation was manifested in the reorganization of the neuromuscular endings, which was followed by their destructive changes in 6-9 days, and a phase of exhaustion with disorders in the fine architectonics of neuromuscular endings after 14 days. The article discusses the peculiarities of the efferent part of the motor unit of the tongue of rats subject to prolonged dehydration.

Keywords: nerve-muscle endings; tongue; muscle fibres; dehydration; rats

\section{Особенности строения двигательных нервных окончаний языка в норме и при дегидратации организма крыс}

\author{
С. Л. Попель*, О. Т. Билоус**, И. В. Билоус* \\ *Прикарпатский национальный университет имени Василя Стефаныка, Ивано-Франковск, Украина \\ **Ивано-Франковский национальный медицинский университет, Ивано-Франковск, Украина
}

Цель исследования - провести аналитический обзор научной литературы по вопросу структуры языка у разных животных и человека, а также изучить особенности строения двигательных нервных окончаний в мышцах языка интактных крыс после длительной дегидратации. Гистологическими методами у 25 половозрелых крыс изучали нервно-мышечные окончания и особенности их распределения в мышцах языка в норме и при дегидратации на протяжении 14 суток. Анализ полученных данных показал разную структуру дифференциированных нервных двигательных окончаний языка крыс в норме, а также выявлены особенности и дана количественная характеристика составляющих компонентов нервно-мышечного окончания в зависимости от продолжительности 
дегидратации. Тип нервно-мышечного окончания отражает тесную морфологическую взаимообусловленную структуру эфферентных нервных проводников в зависимости от отдела языка. Это может определять характер процессов захватывания и пережевывания пищи. Структура нервно-мышечных окончаний мышц кончика языка более дифференцирована, они более многочисленны и большего размера. При этом число ядер и размер нервно-мышечных окончаний мышц кончика языка у крысы больше, чем в других отделах. Это, возможно, определяется скоростью движений языка по причине их питания разной пищей. Число ядер и размер нервно-мышечных окончаний отличается значительными вариациями характера разветления аксона, что определяется анатомическими, физиологическими и биомеханическими условиями функционирования мышц языка у крыс. На основе количественного анализа структурных особенностей аксомышечных синапсов установлено, что мышечные волокна языка имеют нервно-мышечные окончания с заданной синаптоархитектоникой, которая характеризуется спраутингом двигательного аксона, определенной длиной и шириной активных зон, количеством и величиной синаптических складок, числом конечных нейролеммоцитов, особенностью строения субсинаптического участка. Мышечные волокна в теле языка имеют самую сложную пространственную организацию пресинаптического полюса аксомышечных синапсов, больше всего активных зон и синаптических складок. Установлены основные реактивные и деструктивные процессы в нервно-мышечных окончаниях языка, проведено морфологическое обоснование для периодизации этих процессов с выделением отдельных фаз Морфофункциональных изменений при общей дегидратации организма. Комплексный анализ морфофункциональных показателей периферического нервного аппарата языка при общей дегидратации организма позволил выявить в отдельные сроки структурной перестройки нервномышечных окончаний, когда в первые трое суток после начала моделирования дегидратации организма структурным следом адаптации является перестройка нервно-мышечных окончаний, которая сменяется их деструктивными изменениями через 6-9 суток и фазой истощения с нарушением тонкой архитектоники нервно-мышечных окончаний через 14 суток. Обсуждаются особенности эфферентной части двигательной единицы языка при длительной дегидратации.

Ключевые слова: нервно-мышечные окончания; язык; мышечные волокна; дегидратация; крысы

\section{Введение}

Строению периферического нервного аппарата скелетных мышщ посвящено много работ (Bayline et al., 2001; Slaughter et al., 2006; Motoyama et al., 2009). В результате многочисленных исследований структура двигательных нервных окончаний и мионевральных синапсов в разных скелетных мышцах изучена достаточно хорошо (Mu and Sanders, 2010; Zciena et al., 2013).

Существует много данных, в которых устанавлена тесная связь между строением двигательных нервных окончаний с функциональными особенностями иннервируемой скелетной мышцы (Pathi et al., 2012; Tankisi et al., 2013; Zghikh et al., 2014; Simmons, 2017). Однако несмотря на большое количество работ, которые появились в последнее время, исследований, освещающих различный характер морфологии двигательных окончаний языка, очень мало (Yе, 2010; Нua, 2013).

Еще меньше сравнительно-гистологических исследований, которые дают возможность судить о характере изменений мионевральных синапсов в связи с процессами развития организма в разные периоды пре- и постнатального онтогенеза или адаптацией животных к различным условиям существования, а также при различных видах патологии (Bayline et al., 2001; Mu et al., 2013). Что касается сравнительно-гистологических данных о периферическом нервном аппарате языка млекопитающих, то в научной литературе они довольно скудны (Zciena et al., 2013; Dana and McCaughey, 2015). Кроме того, особый интерес изучение двигательных окончаний у крысы имеет потому, что их можно с определенной степенью достоверности перенести на человека, язык которого обладает наиболее тонкими и разнообразными движениями в связи с его участием в артикуляции речи (Amir and Grinfeld, 2011).

Данных о развитии двигательных нервных окончаний в мышцах языка немного. В доступной нам литературе встретились только отдельные работы, касающиеся этих образований у мышей (Suzuki et al., 2012), кошки (Zhang et al., 2001), лошади (Robin et al., 2013) и языка человека в возрастном аспекте (Slaughter et al., 2006). В последнее время появился целый ряд сообщений об изменениях разных тканей в условиях дегидратации организма разного генеза (Mosendz and Mickan, 2012). Отдельные авторы посвятили свои исследования реакции слизистой оболочки языка при дегидратации (Davidova et al., 2016). Особое место среди проявлений данной патологии занимает поражения нервно-мышечного аппарата.

В условиях дегидратации меняется не только метаболизм мышц (Hooper et al., 2014), но и их структура (Mosendz and Mickan, 2012). К сожалению, в доступной научной литературе публикаций о влиянии общей дегидратации организма на структуру и свойства нервно-мышечного аппарата языка мы не обнаружили. К этому времени комплексно не изучались процессы морфофункциональной перестройки мышечных во- локон и нервно-мышечных синапсов в различные сроки при общей дегидратации организма.

Решение этих вопросов позволит выяснить механизм и характер явлений, развивающихся в периферическом нервно-мышечном аппарате, и в значительной степени влиять на них и корректировать водно-электролитный гомеостаз.

Количество жидкости влияет на развитие организма и обеспечивает оптимальные условия его функционирования, которые неразрывно связаны с реализацией биологических и социальных функций человека (Bunn et al., 2014). Она определяет нормальный рост и дифференциацию основных систем организма, способствует наиболее полной реализации генетического потенциала, становлению и формированию вегетативных функций (Hooper and Bunn, 2014). Уровень гидратации начиная с ранних этапов онтогенеза постепенно увеличивает адаптационные ресурсы организма и его функциональные возможности. В пределах допустимого диапазона она создает основу, необходимую для формирования адаптации, которая обеспечивает жизнедеятельность организма в условиях внешней среды. При отсутствии достаточного уровня межклеточной жидкости происходит задержка роста и развития организма и дифференциации его функций, уменьшается резистентность организма к воздействию патогенных факторов (Hooper et al., 2014). Отдельные авторы сообщают о повреждении функции скелетных мышщ в условиях дегидратации, что, очевидно, обусловлено ослаблением механизма физиологической регенерации поврежденных структур мышечных волокон и нейротрофического контроля, который в значительной степени зависит от структурно-функционального потенциала нервно-мышечных синапсов (Mosendz and Mickan, 2012). Однако это положение во многом остается гипотетическим и требует своего подтверждения, особенно морфологическими методами как одним из способов объективизации научных исследований. Все сказанное послужило основой для актуализации данной работы.

Цель исследования - изучить особенности строения периферического нервно-мышечного аппарата языка интактных крыс, а также динамику его морфологической перестройки в условиях общего обезвоживания организма.

\section{Материал и методы исследований}

Материалом исследования послужил язык 25 крыс-самцов. Кусочки брали из корня, тела и кончика обеих сторон языка. Производились продольные и поперечные срезы. Материал обрабатывался по методу Бильшовского - Грос с дополнительной окраской ядер гематоксилином и электронномикроскопическим методом (Mosendz and Mickan, 2012). Для установления особенностей двигательных нервных окончаний в языке определяли площадь двигательного окончания как произведение длины на ширину, что давало возможность сравнивать полученные показатели 
двигательных окончаний во все сроки исследования. Длина моторной бляшки измерялась от начала деления осевого цилиндра на терминальные веточки до конца самых длинных из них, включая и ядра подошвы, расположенные по ходу терминалей. Ширина определялась расстоянием между концами боковых терминалей и имеющимися здесь ядрами шванновской глии. Измерения производили окулярным микрометром под микроскопом МБИ-1 (объектив - ${ }^{\mathrm{x}} 40$, окуляр - ${ }^{\mathrm{x}} 15$ ). Для выяснения особенностей структуры двигательных окончаний подсчитывали терминальные веточки и ядер подошвы. На основании полученных цифровых данных вычислялись средние арифметические.

Контрольная группа состояла из пяти интактных животных. С целью изучения влияния дегидратации на состояние периферического нервно-мышечного аппарата языка проводили полное ограничение питьевого режима в течение 3, 6, 9 и 14 суток. Выживание лабораторных животных составило соответственно 96,0\%, $56,0 \%$ и 4,5\%. Забор материала проводили согласно «Правилам гуманного обращения с экспериментальными животными».

Статистическую обработку данных проводили при помощи програмного пакета Statistica 6 (StatSoft Inc., USA). Использовали непараметрические методы исследования (критерий Уилкоксона, Манна - Уитни). Параметры в таблице и тексте имеют такие обозначения: $\mathrm{x}$ - среднее, SE - стандартная ошибка среднего. Статистические изменения считали вероятными тогда при полученном уровне вероятности отличий $\mathrm{P}<0,05$.

\section{Результаты}

Двигательные нервные окончания встречаются во всех мышечных слоях корня, тела и кончика языка. Нельзя указать на какие-либо существенные различия в структуре двигательных окончаний, которые могли бы быть присущи одному из отделов или определенному мышечному слою языка. Везде двигательные окончания различны по форме, типу ветвления осевого цилиндра, количеству терминальных веточек и ядер, а также по размерам окончаний. Однако двигательные окончания чаще всего встречаются в теле языка. Во всех исследованных отделах языка наблюдаются четыре типа ветвления осевого цилиндра: дихотомический (простой и сложный), рассыпной, магистральный и переходный (рис. 1).
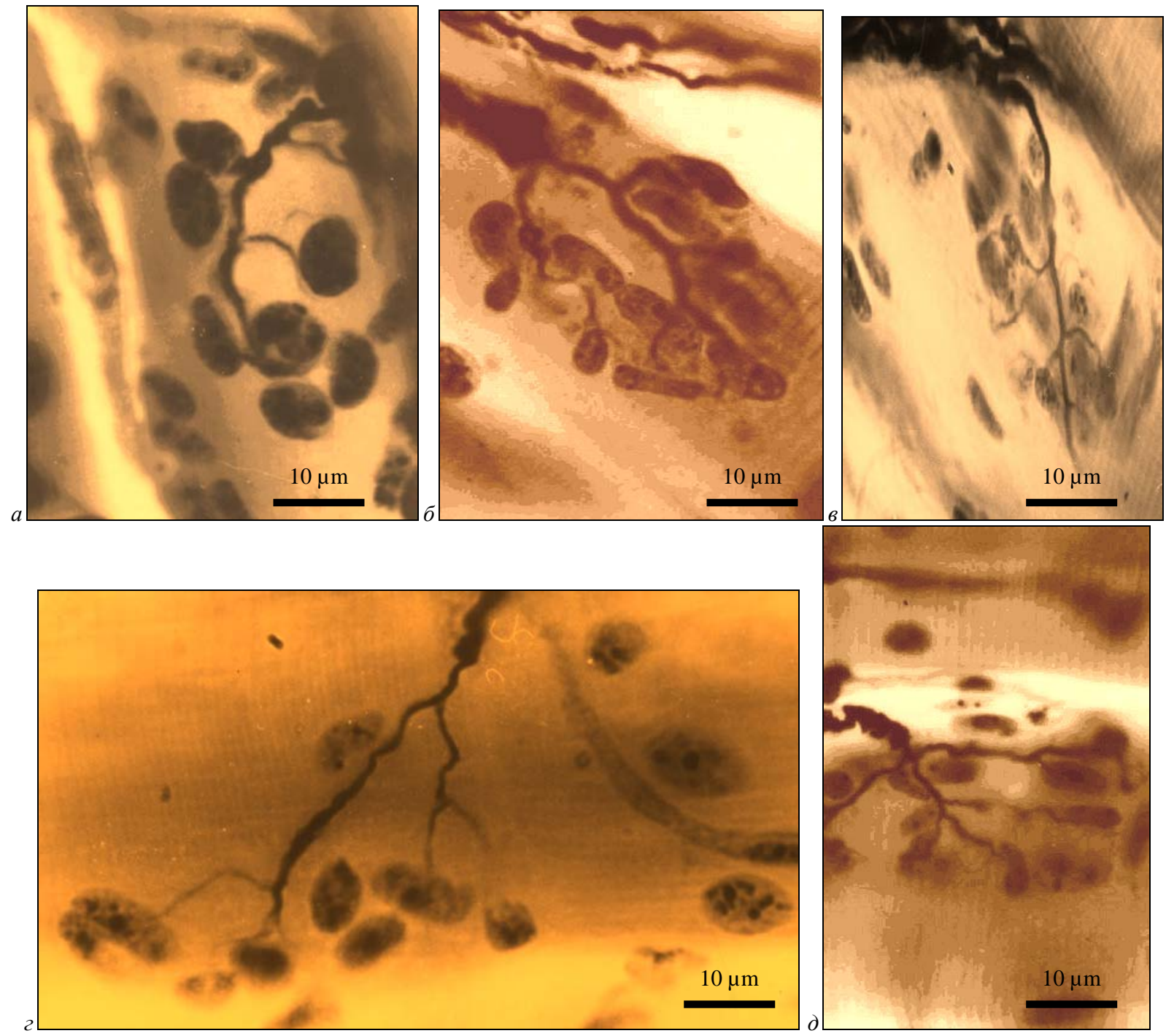

Рис. 1. Основные типы ветвления осевого цилиндра языка половозрелых крыс: $a$ - простой дихотомический, $\sigma$ - сложный дихотомический, 6 - магистральный, 2 - рассыпной, $\partial$ - переходный; импрегнация по Бильшовскому - Грос

Простой дихотомический тип ветвления характеризуется тем, что осевой цилиндр делится только на две терминальные веточки, тогда как при сложном дихотомическом типе основные терминали отдают от себя одну или ряд более мелких веточек. При рассыпном типе ветвления осевой цилиндр сразу делится на несколько веточек. При магистральном типе от ветви, являющейся глав- ным продолжением осевого цилиндра, отходят боковые веточки с одной или двух сторон. Между этими основными типами существует переходный тип ветвления нервных терминалей. Наибольший процент двигательных окончаний простого дихотомического типа ветвления наблюдается в корне $(76,0 \%)$, а наименьший - в кончике языка $(28,4 \%)$ (табл. 1). 
Сумма двигательных окончаний, обладающих наиболее дифференцированными типами ветвления осевого цилиндра, больше всего встречается в кончике $(64,6 \%)$ и корне языка $(75,5 \%)$. Самое большое количество терминальных веточек также наблюдается в кончике $(4,73 \pm 0,05)$, несколько меньше - в теле $(3,52 \pm 0,03)$ и совсем мало в корне языка $(2,12 \pm 0,02)$ (табл. 1).

Размеры и форма ядер в двигательных окончаниях разнообразны. Каждое ядро содержит одно, реже два - три ядрышка. Наибольшее число ядер конечных нейролеммоцитов обнаружено в корне $(10,31 \pm 1,15)$, а наименьшее - на боковой поверхности тела $(4,04 \pm 0,02)$ и кончике $(5,81 \pm 0,04)$ языка. При этом соотношение количества ядер в бляшке в одном отделе языка имеет незначительные колебания (от 8,42 $\pm 0,02$ до 8,71 $\pm 0,05$ ) (табл. 1).

Что касается площади бляшки, то она также оказалась наибольшей в кончике языка $(1028,7 \pm 68,2$ мкм²). Большую площадь бляшки, по сравнению со всеми исследованными отделами языка, за исключением тела, имеют боковые поверхности вблизи кончика $\left(738,9 \pm 23,4\right.$ мкм² $\left.^{2}\right)$ и передняя часть тела языка $(706,5 \pm$ 21,9 мкм $\left.^{2}\right)$. Площадь бляшки имеет самые мелкие размеры в корне

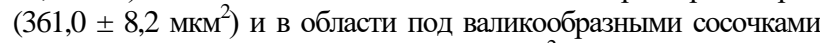

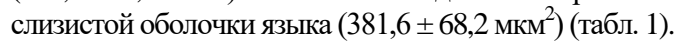

После трех суток дегидратации в претерминальных участках образуются неравномерные расширения и сужения миелиновых нервных волокон, уменьшается площадь разветвления терминальных ветвей двигательного аксона, которые образуют пресинаптический полюс нервно-мышечных синапсов (рис. 2).

Возникновение варикозных деформаций связано с расслоением миелиновой оболочки (рис. 2б). При этом в ядрах нейролеммоцитов происходит конденсация хроматина, частичная вакуолизация цитоплазмы. В аксоплазме возрастает плотность матрикса митохондрий, расширяется периаксональное пространство и неравномерно сужается просвет прилегающих гемокапилляров.

В нервно-мышечных синапсах уменьшается периметр терминалей аксона, длина синаптических контактов, ширины и длины активных зон пресинаптической мембраны, количество синаптических везикул, уплотняется матрикс митохондрий и фрагментируются кристы. Со стороны постсинаптических структур необходимо отметить увеличение расстояния между синаптическими складками, что обусловлено их разрушением. По сравнению с контрольными показателями после 6-суточной дегидратации меняется топография эфферентных миелиновых волокон, и особенно их претерминальных отделов, растет частота и величина неравномерных расширений и сужений, уменьшается как первичный, так и вторичный спраутинг двигательных аксонов.
При электронномикроскопическом исследовании обнаружено, что в миелиновых волокнах расширяется периаксональное пространство, в аксоплазме возрастает степень агрегации филаментозно-тубулярных структур. При этом в цитоплазме нейролеммоцитов значительно увеличивается количество вакуолей, отражающее критические процессы захвата количества жидкости из межклеточного пространства, а миелиновая оболочка имеет множественные участки расслоения ламелл миелина.

В нервно-мышечных синапсах 6-суточная дегидратация вызывает дезинтеграцию большинства складок постсинаптической мембраны, расширение синаптической щели и врастание в нее отростков конечных нейролеммоцитов (рис. 3). В аксональных терминалях уменьшается число везикул и синаптических пузырьков, они приобретают разную величину, среди которых преобладают везикулы малого диаметра. Митохондрии малочисленные и, как правило, имеют просветленный матрикс и разрушеные кристы. В постсинаптическом отделе уменьшается (до 64,8\%) количество синаптических складок, расстояние между ними увеличивается, ширина и длина активных зон уменьшаются соответственно на $66,6 \%$ и $46,7 \%$. Вышеописанные изменения характерны для всех типов мышечных волокон языка, однако наибольшую устойчивость к патогенетическому воздействию дегидратации проявляют медленные оксидативные мышечные волокна, самую низкую быстрые гликолитические, а быстрые окислительно-гликолитические мышечные волокна занимают промежуточное положение. Именно поэтому в таблице 2 представлены данные морфометрического аннализа основных структурных компонентов нервномышечных синапсов только быстрых гликолитических волокон.

Продление срока полного ограничения питьевой воды до 9 суток приводит к дегенеративному распаду отдельных эфферентных волокон и терминальных разветвлений двигательного аксона, что вызывает денервацию мышечных волокон. При этом в области нервно-мышечного контакта уменьшается количество нейролеммоцитов и аргирофилия их ядер (рис. 4).

Средняя площадь нервно-мышечного контакта уменьшается по сравнению с контролем на $65,6 \%$, а по сравнению с данными предыдущего срока эксперимента - на 33,2\%. Нервно-мышечные синапсы двигательных аксонов в быстрых гликолитических мышечных волокнах перегружены синаптическими пузырьками. Их количество на весь срез через активную зону синапса возрастает на $58,0 \%$ по сравнению с контрольными показателями и на $350,0 \%$ больше, чем на этапе 6-суточной дегидратации. В субсинаптической зоне выявляется меньшее количество рибо- и полирибосом, а также пиноцитозных пузырьков.

\section{Таблица 1}

Относительное распределение разных типов ветвления осевых цилиндров и соотношение составных елементов двигательных бляшек в языке интактных крыс (n=5)

\begin{tabular}{|c|c|c|c|c|c|c|c|c|}
\hline \multirow{3}{*}{ Отдел языка } & \multicolumn{5}{|c|}{ Типы ветвления осевого цилиндра, \% } & \multirow{3}{*}{$\begin{array}{c}\text { Количество } \\
\text { веточек в } \\
\text { бляшке }\end{array}$} & \multirow{3}{*}{$\begin{array}{c}\text { Количество } \\
\text { ядер в } \\
\text { бляшке }\end{array}$} & \multirow{3}{*}{$\begin{array}{c}\text { Площадь } \\
\text { бляшки, мкм² }\end{array}$} \\
\hline & \multicolumn{2}{|c|}{ дихотомический } & \multirow{2}{*}{ рассыпной } & \multirow{2}{*}{ магистральный } & \multirow{2}{*}{ переходный } & & & \\
\hline & простой & сложный & & & & & & \\
\hline Кончик & 64,61 & 2,12 & 16,63 & 6,51 & 10,14 & 4,73 & 8,89 & 659,6 \\
\hline Тело & 49,72 & 12,34 & 15,66 & 12,28 & 10,01 & 3,52 & 6,46 & 540,2 \\
\hline Корень & 75,46 & 8,22 & 16,32 & 0,00 & 0,00 & 2,12 & 4,17 & 381,5 \\
\hline
\end{tabular}

Таблица 2

Гистометрическая характеристика нервно-мышечных синапсов быстрых гликолитических мышечных волокон языка в разные сроки экспериментальной дегидратации организма крыс $(\mathrm{x} \pm \mathrm{SE}, \mathrm{n}=5)$

\begin{tabular}{|c|c|c|c|c|c|}
\hline \multirow{2}{*}{ Структурные элементы и их параметры } & \multirow{2}{*}{ Контроль } & \multicolumn{4}{|c|}{ Длительность эксперимента } \\
\hline & & З суток & 6 суток & 9 суток & 14 суток \\
\hline Периметр терминалей, мкм & $7,23 \pm 0,81$ & $4,02 \pm 0,34^{*}$ & $4,26 \pm 0,32$ & $3,66 \pm 0,24$ & $3,22 \pm 0,26^{*}$ \\
\hline Длина синаптического контакта, мкм & $2,88 \pm 0,22$ & $1,42 \pm 0,24$ & $0,83 \pm 0,007$ & $0,62 \pm 0,002^{*}$ & $0,55 \pm 0,003^{*}$ \\
\hline Количество складок постсинаптической мембраны & $10,64 \pm 1,26$ & $6,11 \pm 1,23$ & $3,87 \pm 0,9^{*}$ & $1,51 \pm 0,23^{* *}$ & $1,11 \pm 0,01^{*}$ \\
\hline Расстояние между складками, мкм & $0,21 \pm 0,01$ & $0,41 \pm 0,01$ & $0,65 \pm 0,01$ & $0,92 \pm 0,01^{*}$ & $0,98 \pm 0,01^{* *}$ \\
\hline Длина отдельной складки, мкм & $2,87 \pm 0,15$ & $2,22 \pm 0,12$ & $1,61 \pm 0,09^{* *}$ & $1,25 \pm 0,03$ & $1,12 \pm 0,02^{*}$ \\
\hline Ширина активной зоны, мкм & $0,22 \pm 0,01$ & $0,19 \pm 0,01$ & $0,17 \pm 0,01$ & $0,16 \pm 0,01$ & $0,14 \pm 0,01 * *$ \\
\hline Длина активной зоны, мкм & $0,85 \pm 0,03$ & $0,57 \pm 0,01$ & $0,45 \pm 0,01$ & $0,27 \pm 0,01$ & $0,21 \pm 0,01 * *$ \\
\hline Количество везикул на весь срез через активную зону & $165,4 \pm 17,5$ & $101,3 \pm 12,4^{*}$ & $71,2 \pm 16,8^{* *}$ & $320,4 \pm 52,2$ & $120,0 \pm 30,2^{*}$ \\
\hline Количество везикул в области активной зоны & $10,69 \pm 0,47$ & $6,24 \pm 0,32$ & $4,25 \pm 0,27$ & $2,83 \pm 0,21^{*}$ & $2,11 \pm 0,14^{*}$ \\
\hline
\end{tabular}

Примечание: *- $\mathrm{P}<0,05 ;$ ** - $\mathrm{P}<0,01$ по сравнению с предыдущим этапом эксперимента. 


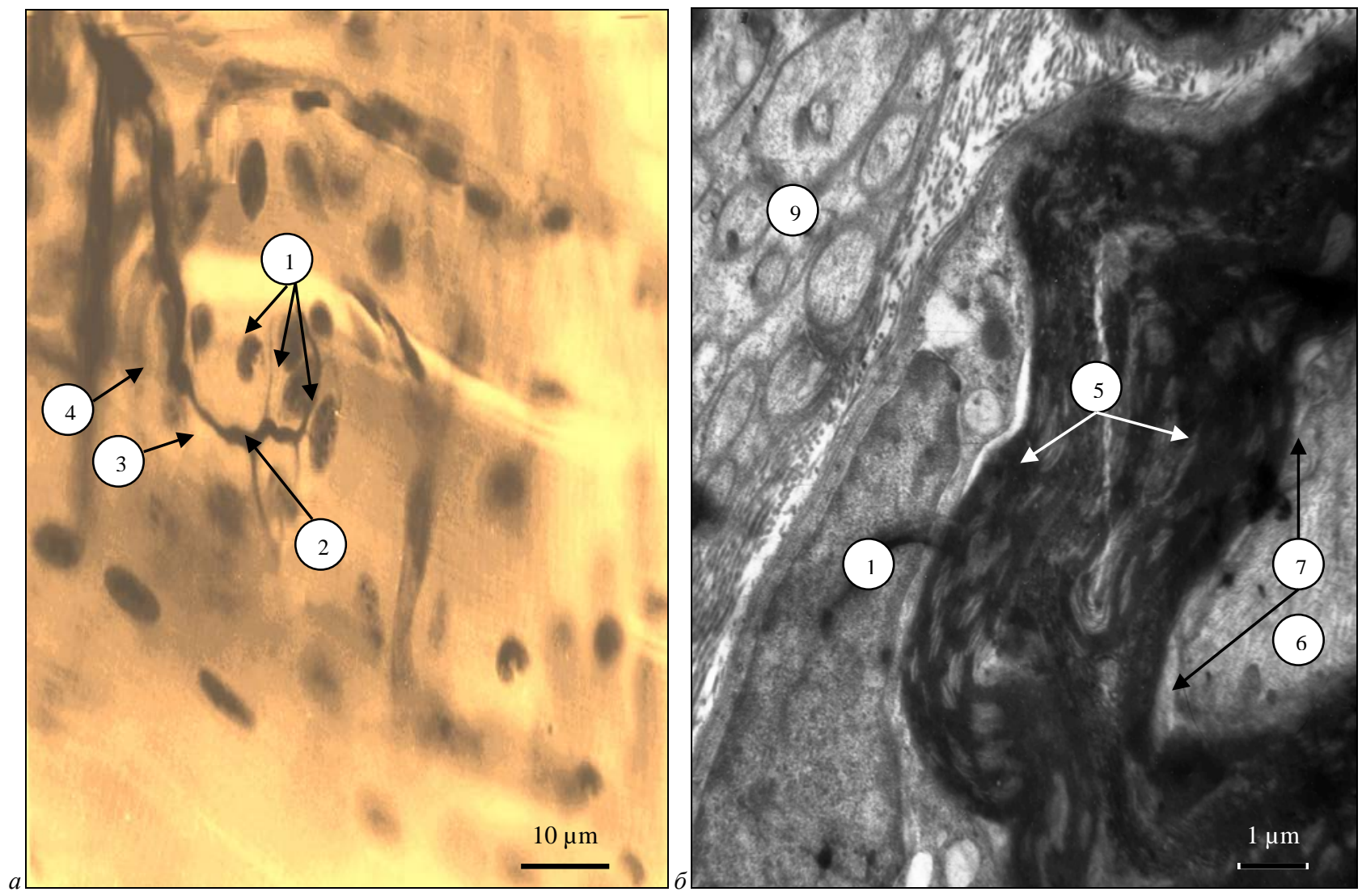

Рис. 2. Гистоструктурная (a) и ультраструктурная (б) организация периферического нервного аппарата собственных мышц языка через 3 суток после начала моделирования дегидратации: импрегнация по Бильшовському - Грос: 1 - нейролеммоциты; 2 - терминальные ветвления; 3 - сужение претерминалей; 4 - варикозное расширение претерминалей; 5 - миелиновая оболочка; 6 - аксон; 7 - периаксональное пространство; 8 - гемокапилляр; 9 - безмиелиновое нервное волокно

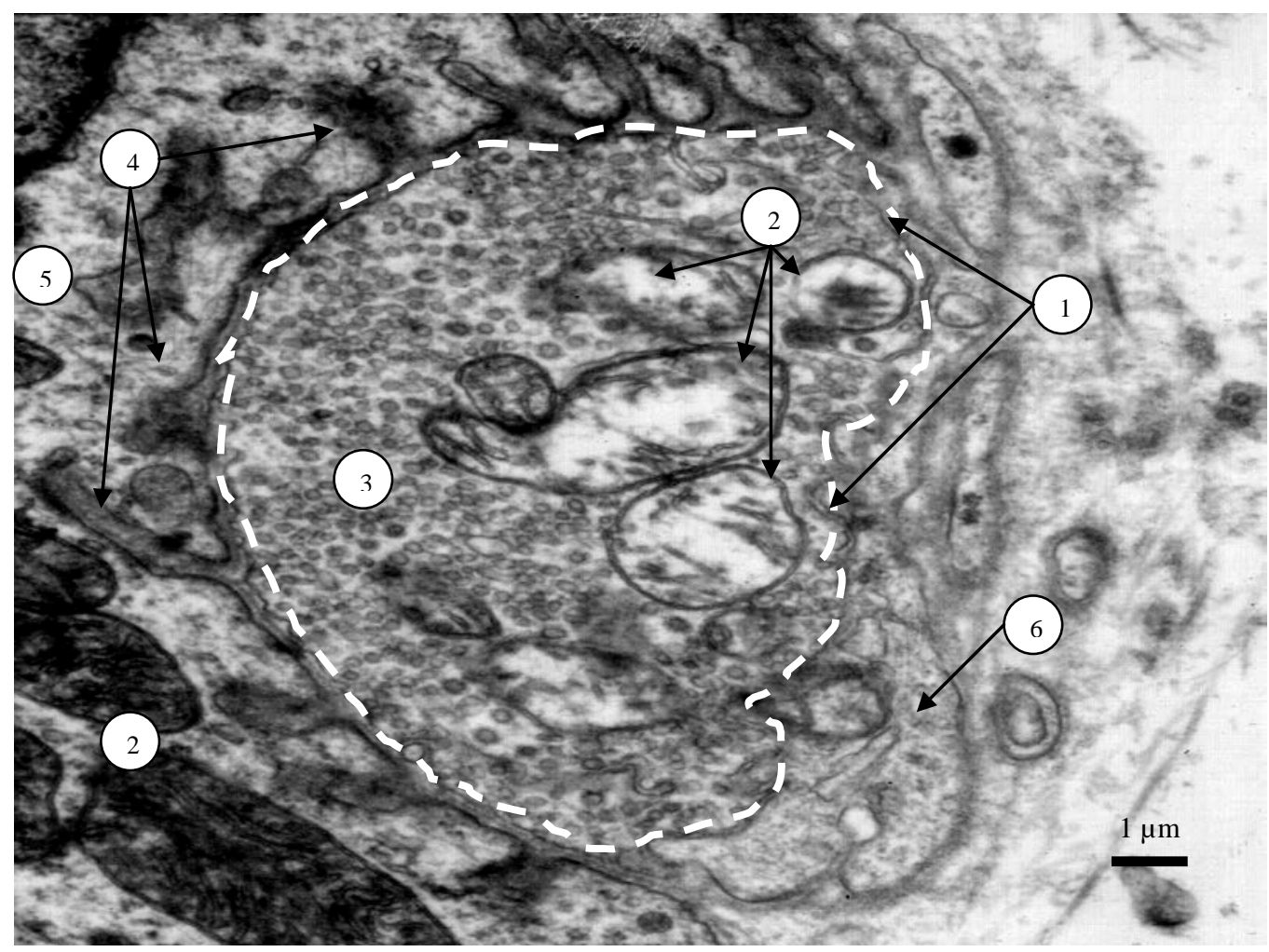

Рис. 3. Ультраструктура аксо-мышечного синапса через 6 суток после начала моделирования дегидратации:

1 - пресинаптический полюс АМС (контуры обведены пунктирной линией), 2 - митохондрии, 3 - синаптические везикулы, 4 - постсинаптические складки, 5 - мышечное волокно, 6 - нейролеммоцит 


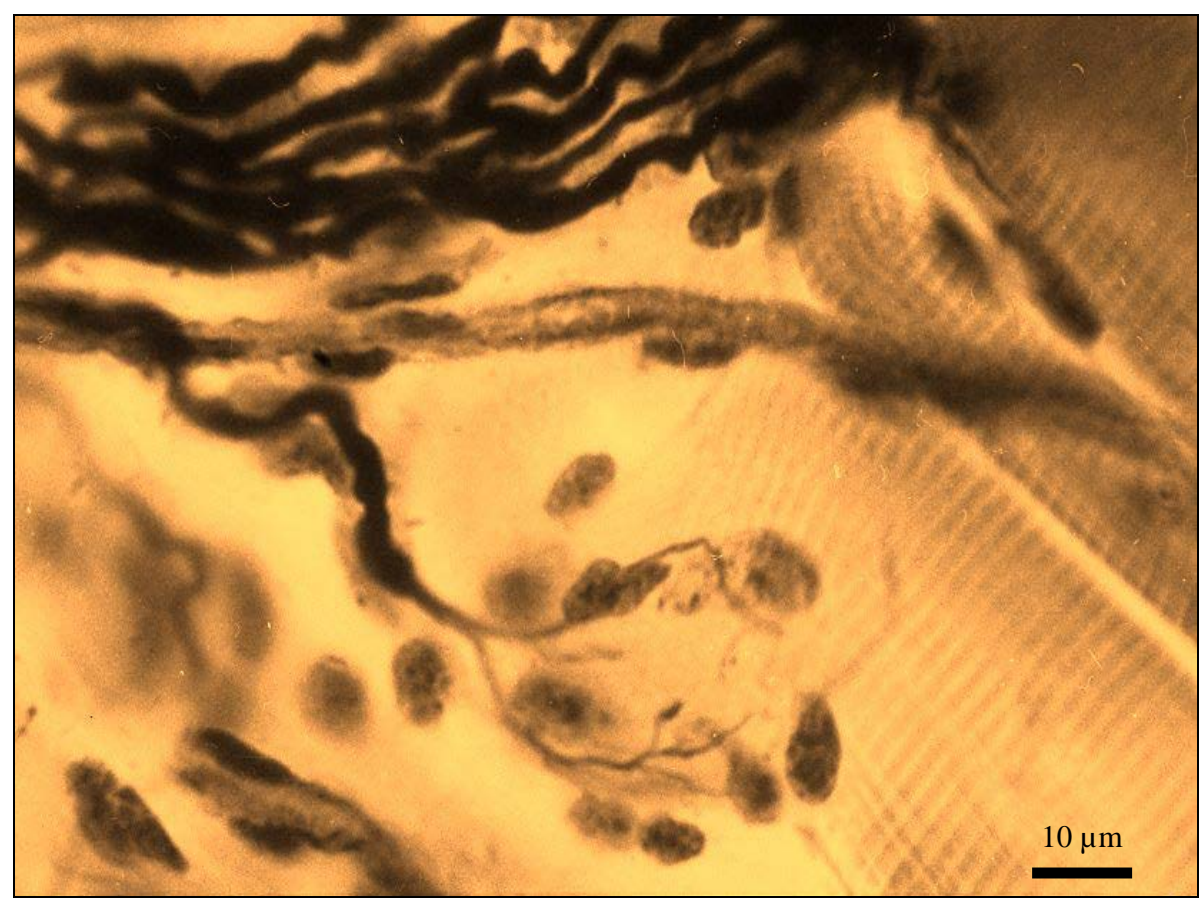

Рис. 4. Нарушение правильного контура миелиновой оболочки в области претерминалей двигательного нервного волокна через 9 суток после начала моделирования дегидратации: импрегнация по Бильшовскому - Грос

При этом незначительное количество пиноцитозных пузырьков, которые находятся в цитоплазме, проникают туда вследствие деструкции постсинаптической мембраны. Гистометрический анализ и исследования ультраструктуры нервно-мышечных синапсов быстрых окислительно-гликолитических и медленных окислительных мышечных волокон показал, что у них тоже появляется тенденция к уменьшению количества пиноцитозных пузырьков, длины синаптического контакта, количества синаптических складок, ширины и длины активных зон пресинаптической мембраны. На данном этапе эксперимента наблюдается формирование так называемых атрофических синапсов, для которых характерным признаком является полное отсутствие складок в постсинаптической мембране.

Особенность строения нервно-мышечных синапсов большинства мышечных волокон языка заключается в том, что пресинаптический полюс образован отдельными терминалями. Последние содержат относительно малое количество синаптических пузырьков, отсутствуют четко сформированные активные зоны. При этом терминали образуют расширенные аксон-нейролеммоцитные и аксон-аксонные щелевидные контакты.

Ограничение питьевого режима в течение 12 суток ведет к массивному разрушению нервно-мышечных окончаний, гомогенизации миелиновых оболочек и атрофии терминальных разветвлений аксонов (рис. 5).

Аксоплазма имеет повышенную электронно-оптическую плотность, в ней отсутствуют нейрофиламенты и другие специфические включения. В нервно-мышечных синапсах терминальные ветвления разрушаются, в результате чего пресинаптический полюс нервно-мышечных контактов прекращает свое существование. В этих участках наблюдаются остатки аксоплазмы. В связи с тотальной деструкцией ультраструктур аксо-мышечных синапсов на данном этапе эксперимента гистометрические исследования провести не удалось. Что касается синапсов атрофичных мышечных волокон, то для их терминалей характерно периферическое расположение синаптических пузырьков с одновременным образованием обширных пустот в центральной части нервных терминалей. Синаптические везикулы через поврежденные участки пресинаптической мембраны попадают в субсинаптическую зону, которая, как и на предыдущем этапе исследования, имеет примитивную архитектуру.

\section{Обсуждение}

Данные об эмбриональном и постэмбриональном развитии двигательных нервных окончаний в организме животных и человека (Bayline et al., 2001) свидетельствуют о том, что наиболее примитивным типом ветвления осевого цилиндра является простой дихотомический, а более дифференцированными - рассыпной и магистральный тип ветвления нервных терминалей.

Полученные нами данные свидетельствуют о разнице в строении двигательных окончаний в разных отделах языка у одного и того же животного. При этом большинство двигательных окончаний имеет простой дихотомический тип ветвления (76,0\%), а магистральный и переходный совсем отсутствуют. По имеющимся данным литературы, форма двигательных окончаний в мышщах языка у большинства млекопитающих довольно однообразна (Mu and Sanders, 2010). Например, Knittel and Kent (2005), исследовавшие двигательные окончания языка у представителей класса рыб, также отмечает удивительное сходство в их строении.

Однако авторы многочисленных работ, посвященных изучению двигательных нервных окончаний в скелетных мышщах животных, ограничиваются, как правило, лишь общим описанием двигательных окончаний и не анализируют их подробности (Simmons, 2017). Лишь сравнительно недавно Guttridge (2012) обратил внимание на изменение количества специфических ядер двигательного окончания при различных условиях деятельности мышц.

В работах Zhang et al. (2001) и Zciena et al. (2009) описываются уже не только изменение количества ядер, но и числа терминальных веточек, а также отмечаются вариации размеров двигательных окончаний и характера ветвления осевого цилиндра в мышщах, различающихся анатомическими, физиологическими, топографическими или биомеханическими условиями функционирования.

Основываясь на работах Bayline et al. (2001) и Zciena (2013), мы считаем, что для выявления разницы в строении двигательных бляшек у ряда животных необходимо тщательное исследование отдельных структур элементов, составляющих бляшку, ее размеров, характера ветвления осевого цилиндра. Это тем более необходимо, что и по результатам наших наблюдений, резких видовых различий в строении двигательных окончаний не обнаруживается. Мы считаем, что цифровые данные, полученные в результате такого исследования, могут, по-видимому, характеризовать степень дифференцирования двигательного окончания. 


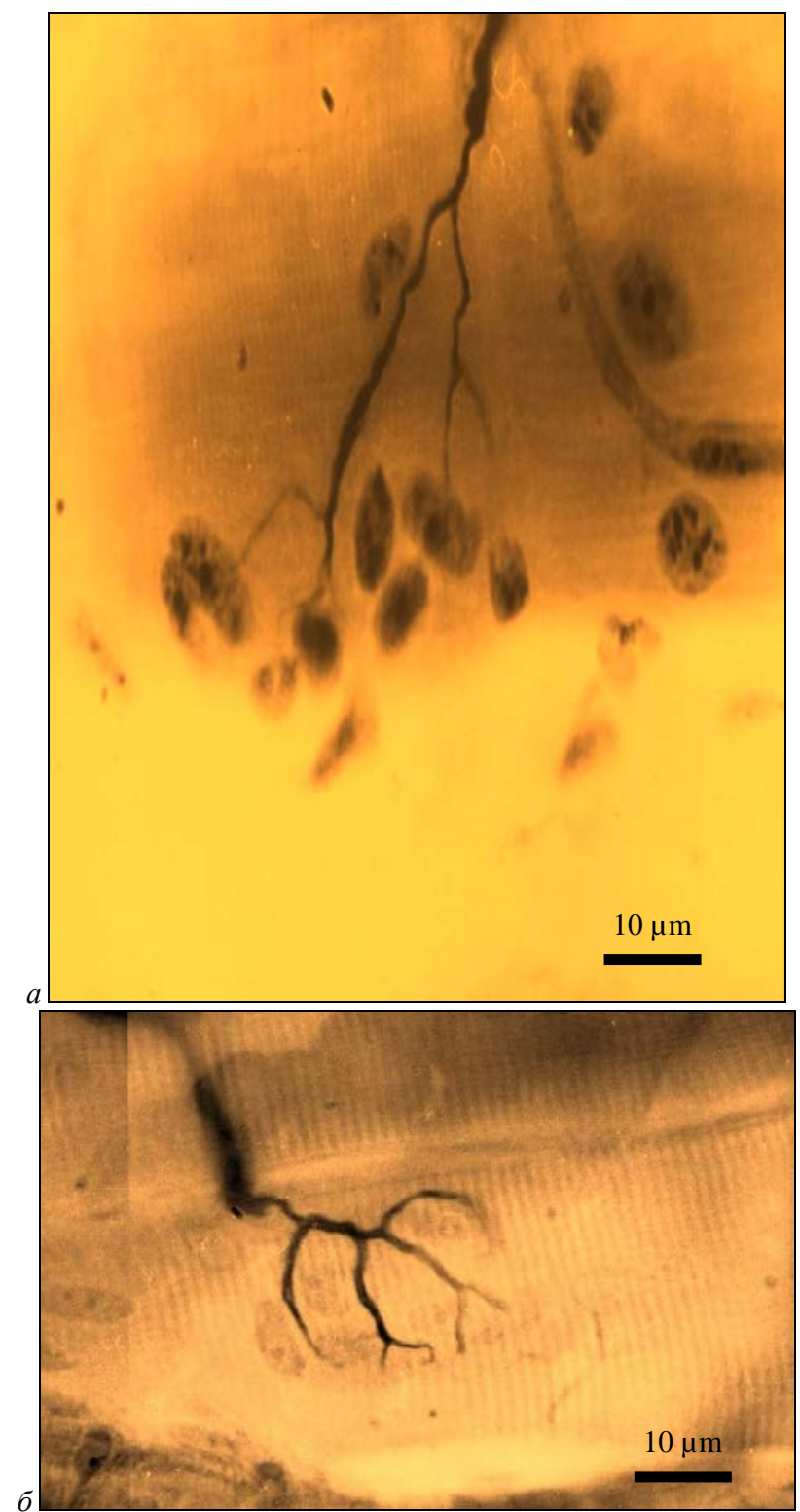

Рис. 5. Структура терминальных разветвлений нервномышечного окончания в контрольной группе животных $(a)$ и их дегенеративный распад на 14-е сутки после начала моделирования дегидратации (б): импрегнация по Бильшовскому - Грос

Из работ Gaffield et al. (2011) и Simmons (2017) известно, что в нервно-мышечном синапсе происходит изменение обмена веществ при передаче возбуждении с нерва на мышцу. Активность мионеврального синапса зависит как от количества терминальных веточек и ядер бляшек, так и от ее размеров. Об этом свидетельствуют работы Knittel and Kent (2005), показавших, что характерной особенностью двигательных окончаний является высокая концентрация и активность локализованных в ней энзимов по сравнению с нервными и мышечными волокнами. При этом Мu et al. (2013) подчеркивают, что ферменты, необходимые для специфической деятельности нервных элементов, распределяются преимущественно в производных шванновской глии. В результате ветвления осевого цилиндра значительно увеличивается поверхность нервных волокон, контактирующих с протоплазмой шванновского симпласта.

Данные вышуказанных авторов подтверждаются также экспериментами других исследователей (Johnson and Connor, 2011), которые отмечают, что в зависимости от режима мышечной деятельности происходит увеличение или уменьшение количества терминальных веточек, ядер и площади двигательного окончания.
Сравнивая данные научной литературы (Motoyama et al., 2009; Suzuki et al., 2012; Dana and McCaughey, 2015) и результаты собственного исследования, мы пришли к выводу, что, по сравнению с мышами, двигательные бляшки языка крысы имеют довольно большие размеры (соответственно 212,3 $\pm 4,8$ и 540,1 \pm 9,1 мкм²), содержат большее количество ядер (соостветсвенно 4,9 $\pm 0,05$ и $6,3 \pm 0,07)$ и дифференцированные типы ветвления осевого цилиндра (рассыпной и магистральный)

По мнению Bayline et al. (2001), Gaffield et al. (2011) и Zghikh et al. (2014), это разнообразие вариаций в строении двигательных окончаний в языке млекопитающих связано с тем, что отдельные отряды и виды этого класса в процессе дивергентной эволюции приспособились к определенным условиям существования. В связи с этим различной оказывается и функция языка. Работами многих авторов (Suzuki et al., 2012; Simmons, 2016) на разнообразном фактическом материале показано, что изменение функции органа влечет за собой и изменение его структуры. На основании этого можно предположить, что структура двигательных окончаний в языке также связана с особенностью его функции. Однако необходимо подчеркнуть, что учесть особенности функции языка значительно труднее, чем скелетных мышщ, тем более что в научной литературе такие данные отсутствуют.

Чтобы иметь возможность хотя бы в общих чертах судить о функции языка у животных, мы учитывали не только характер его движения во время питания, но и наличие ряда дополнительных действий. Анализируя данные, касающиеся строения двигательных окончаний языка крысы, прежде всего укажем на ясно выраженные существенные топографические различия: двигательные окончания кончика языка являются более дифференцированнными, то есть в них имеется значительно больше терминальных веточек и ядер в бляшках, чем в корне. Площадь двигательного окончания также значительно больше в теле языка. Кроме того, большинство двигательных окончаний тела языка обладают наиболее дифференцированными типами ветвления осевого цилиндpa, в то время как в корне большинство бляшек - простого дихотомического типа

Из данных научной литературы известно, что характер питания животных существенно отличается. Ряд авторов (Amir and Grinfeld, 2011; Simmons, 2017) указывают, что чем сложнее механизм захватывания пищи, тем более быстрые движения языка требуются и тем более сложный тип ветвления нервно-мышечных окончаний.

В строении двигательных окончаний языка исследованных представителей парнокопытных также наблюдаются различия: количество ядер и средняя площадь бляшки оказались больше у свиньи (Liu, 2009), чем у овцы (Choy, 1986). По-видимому, это можно связать с тем, что язык свиньи играет роль хватательного органа во время приема корма, тогда как у овцы функцию захватывания пищи выполняют губы.

В соответствии с этими данными интересны результаты исследования Pfeiffer et al. (2000) и Zciena et al. (2009), которые нашли, что ядро подьязычного нерва и мышщы языка более развиты у коровы и свиньи, чем у лошади, губы которой выполняют функцию захватывания корма, как и у овцы.

Сравнивая представителей разных отрядов, например, грызунов и хищных, можно отметить, что двигательные окончания в языке хищных более дифференцированны. Это, по-видимому, можно связать с разнообразным характером деятельности мышщ языка. Помимо обычной функции, характерной для всех животных, язык хищников выполняет ряд дополнительных действий. Например, язык кошки, благодаря ороговеванию нитевидных сосочков, помогает животному сдирать мясо с костей и удерживать добычу в ротовой полости. Язык собаки является отчасти органом терморегуляции.

Что касается двигательных окончаний языка человека, то многие исследователи предполагали, что двигательные окончания в языке человека в связи с участием его в акте членораздельной речи будут более дифференцированными, чем у других исследованных животных (Motoyama et al., 2009; Johnstone et al., 2010). 
В действительности оказалось, что наибольшей степени дифференцированности двигательные окончания достигают у ежа, совершающего чрезвычайно быстрые движения языком. Возникает предположение, что увеличение количества веточек, ядер и площади двигательного окончания связано, очевидно, в первую очередь с быстротой и интенсивностью, а не с тонкостью и разнообразием движений. Эти последние зависят, вероятно, от деятельности высшего отдела центральной нервной системы - коры головного мозга.

Следует подчеркнуть, что предположение о значении быстроты и интенсивности в сокращении мышщ для формирования двигательных окончаний требует еще дальнейшего подтверждения.

Таким образом, обнаружено постепенное усложнение строения двигательных окончаний языка в норме, что зависит от их топографии. По нашему мнению, такая сложность и разнообразие нервно-мышечного аппарата языка у крыс должны отразиться на его реакции на самые разнообразные факторы как в норме, так и при патологии. Об этом свидетельствуют полученные нами данные экспериментального исследования, которые показали, что реакция нервно-мышечных окончаний на дегидратацию проявляется на всех уровнях их организации и имеет четко выраженную динамику. Сравнение ультраструктуры конечных нейролеммоцитов контрольных и подопытных животных показало ряд характерных изменений, которые свидетельствуют о развитии стресс-реакции в этих клетках в ответ на дегидратацию. Сравнительный анализ наших данных и данных научной литературы показал, что компенсаторно-приспособительные реакции нейролеммоцитов при дегидратации проявляются гипотрофией таких морфологических структур, которые обеспечивают достаточный уровень синтетических процессов в норме (Slater, 2015).

Обнаруженные нами электронномикроскопически признаки деструкции миелиновых волокон в виде расширения периаксонального пространства и высокая степень агрегации филаментознотубулярних структур в аксоплазме позволяют говорить о нарушении аксонного транспорта (Kuznetsov and Kuznetsov, 2014). Агрегация микротрубочек и нейрофиламентов может проходить в условиях повышенной кислотности аксоплазмы. Такое «закисление», очевидно, является результатом искаженной функции нейролеммоцитов, которые находятся в неадекватных условиях и выделяют в окружающую среду кислый белок (Gaffield et al., 2011). При этом в цитоплазме нейролеммоцитов и в аксоплазме нервных терминалей значительно увеличивается количество вакуолей и везикул разного диаметра, что свидетельствует о критическом уровне захвата жидкости из межклеточного пространства. При этом миелиновая оболочка имеет множественные участки расслоения ламелл миелина. Такая деградация миелиновой оболочки является показателем глубокого нарушения обмена фосфолипидов (Nawaz et al., 2013).

Уменьшение количества митохондрий, среди которых преобладают органеллы с матриксом низкой электронно-оптической плотности и редуцированными кристами следует трактовать как признак нарушения окислительного метаболизма при длительной дегидратации (Bunn et al., 2014). Поскольку в этом процессе митохондрии принимают непосредственное участие, можно предположить, что атрофия мышщ языка обусловлена нарушением активного транспорта нейромедиатора в результате дефицитного энергообеспечения аксо-мышечной передачи нервного импульса. При этом морфологическим субстратом нарушения окислительного фосфориллирования является фрагментация и редукция крист, которая проявляется снижением активности сукцинатдегидрогеназы. Набухание митохондрий в отдельных участках аксо-мышечного синапса, очевидно, является результатом компенсаторно-приспособительной реакции, направленной на усиление их функциональной активности (Pathi et al., 2012). Подтверждение этого положения можно найти в более ранней работе Holstege and Kuypers (1987), где авторадиографическим методом выявлено рост синтеза ДНК в набухших митохондриях.

Если учесть, что число везикул нейромедиатора и количество митохондрий в пресинаптической области аксона зависит, с одной стороны, от синтетической активности нейрона (Mu, 2013), а с другой - от аксонного транспорта (Kuznetsov and Kuznetsov, 2014), выявленное нами существенное уменьшение периметра терминалей и длины синаптического контакта может выступать в роли третьего и не менее важного фактора, влияющего на снижение интенсивности процессов передачи нервного возбуждения в условиях дегидратации.

Вышеописанные изменения характерны для всех типов мышечных волокон языка, однако наибольшую устойчивость к патогенетическому воздействию дегидратации проявляют нервные окончания в медленных оксидативных мышечных волокнах, самую низкую - в быстрых гликолитических, а в быстрых окислительно-гликолитических мышечных волокнах занимают промежуточное положение.

Продление срока полного ограничения питьевой воды до 9 суток приводит к дегенеративному распаду отдельных эфферентных волокон и терминальных разветвлений двигательного аксона, что вызывает денервацию мышечных волокон. При этом их целостность некоторое время может поддерживаться мембранными рецепторами инсулина, количество которых возрастает при дегидратации и денервации мышечного волокна (Johansson and Arnqvist, 2006). Отмеченное нами уменьшение количества нейролеммоцитов и аргирофилия их ядер в области нервно-мышечного контакта не является специфическим явлением, поскольку похожие изменения наблюдали (Gaffield et al., 2011; Simmons, 2016) при нарушениях другого генеза.

Следует отметить, что прогрессирующее уменьшение площади нервно-мышечного контакта в комплексе с увеличением количества синаптических пузырьков в нервно-мышечных синапсах быстрых гликолитических терминалей двигательных аксонов свидетельствует о хроническом нарушении механизма экзоцитоза ацетилхолина через пресинаптическую мембрану. Аналогичное явление наблюдается при развитии миастенического синдрома (Tankisi et al., 2013).

Гистометрический анализ и исследования ультраструктуры нервно-мышечных синапсов быстрых окислительно-гликолитических и медленных оксидативных мышечных волокон показал, что у них тоже появляется тенденция к уменьшению количества пиноцитозных пузырьков, синаптических складок, ширины и длины активных зон пресинаптической мембраны, а также к уменьшению длины синаптического контакта в целом.

На данном этапе эксперимента мы наблюдали формирование так называемых атрофических синапсов, для которых характерным признаком является полное отсутствие складок в постсинаптической мембране. Уменышение складчатости мембраны ведет к сужению ее площади, а значит, к снижению количества холинорецепторов, исчезновению дополнительной площади для инактивации медиатора с помощью ацетилхолинэстеразы и уменьшению количества Na-К-АТФ-азы, которая обеспечивает местную реполяризацию постсинаптической мембраны (Fritz and Müller, 2007). Пресинаптическая мембрана в этой ситуации обеспечивает экзоцитоз ацетилхолина как в активных, так и в неактивных зонах. Подобное явление описано в работе Rothman (2013) при действии токсинов, которые блокируют экзоцитоз медиатора.

Особенность строения нервно-мышечных синапсов большинства мышечных волокон заключается в том, что пресинаптический полюс образован отдельными терминалями. Последние содержат относительно малое количество синаптических пузырьков, отсутствуют четко сформированные активные зоны. При этом терминали образуют расширенные аксон-нейролеммоцитные и аксонаксонные щелевидные контакты. Учитывая динамику образования атрофических синапсов и вышеприведенные данные, можно сделать вывод о широком участии нейролеммоцитов в процессе дегидратации мышечных волокон. Мы предполагаем, что после разрушения аксонных терминалей нейролеммоциты тормозят синтез и структурирование в матриксе синаптической щели вещества или веществ, которые определяют запуск механизмов роста аксона, а затем и его торможения при контакте с базальной пластинкой бывшего синапса. Таким фактором может быть снижение 
концентрации вещества Р, фактора роста аксонов и других биологически активных веществ (Moore and Goldberg, 2011). Однако образование эффективных синапсов и длительное поддержание их нормальной структуры в условиях дегидратации невозможно, поскольку требует воздействия прогностических факторов роста миотрофинов. В условиях подавления физиологического обмена межклеточной жидкости в мышечных волокнах при ограничении поступления питьевой воды аксоны, хотя и реиннервируют «старую» базальную пластинку, пробыв на ней некоторое время, исчезают из зоны бывшего синапса.

Ограничение питьевого режима в течение 12 суток ведет к массивному разрушению нервно-мышечных окончаний, гомогенизации миелиновых оболочек, атрофии терминальных разветвлений аксонов. Аксоплазма электронноплотная, в ней отсутствуют нейрофиламенты и другие специфические включения. Такие дегенеративные изменения свидетельствуют о существенном нарушении в системе аксонного транспорта. Нейротрофическое влияние мотонейрона на мышечные волокна в значительной степени зависит от системы аксонного транспорта. На это указывает ряд исследований при его фармакологической блокаде (García et al., 2013). Поэтому деструктуризация аксоплазмы при дегидратации следует расценивать как фактор, который ослабляет нейротрофический контроль на мембрану мышечного волокна. Для реализации нейротрофического контроля большое значение имеет секреция ацетилхолина (Bayline et al., 2001; Suzuki et al., 2012), который является обязательным фактором для выделения из терминальной аксоплазмы специфических трофогенов (Moore and Goldberg, 2011).

В нервно-мышечных синапсах терминальные ветвления разрушаются, в результате чего пресинаптический полюс нервно-мышечных контактов прекращает свое существование. В этих участках наблюдаются остатки аксоплазмы. Постоянным признаком при всех формах и степенях нейро- и миопатии является недостаточность активной передачи импульса в зоне пресинаптической мембраны (Mu, 2013). Результаты, полученные нами, показывают, что при дегидратации к имеющимся деструктивным изменениям претерминальных волокон и аксонных терминалей присоединяется недостаточность передачи импульсов, которая обусловлена глубокими дегенеративными изменениями в постсинаптических мембранах, которые усиливают влияние других неблагоприятных факторов на состояние поперечнополосатых мышщ языка. В связи с тотальной деструкцией ультраструктур аксомышечных синапсов на данном этапе эксперимента гистометрические исследования провести не удалось.

\section{Выводы}

В языке крысы наблюдаются следующие типы ветвления осевого цилиндра двигательного окончания: дихотомический (простой и сложный), рассыпной, магистральный и переходный. Степень развития двигательных нервно-мышечных синапсов языка (количество терминальных веточек и ядер, а также площадь бляшки) различна в разных отделах языка в связи с тем, что в процессе дивергентной эволюции отдельные части языка млекопитающих приспособились к различным условиям захвата и пережевывания пищи. Увеличение количества терминальных веточек, ядер и площади двигательного окончания связано в первую очередь с быстротой, а не с тонкостью и разнообразием движений иннервируемого органа.

Патоморфологические изменения при дегидратации организма отражают тесное взаимодействие нервно-мышечных окончаний при метаболической, реактивной и дистрофической перестройке мышечных волокон при общей дегидратации организма. Неодинаковая степень их выраженности связана с существованием в составе мышщ языка различных мышечных волокон, причем преобладают мышечные волокна промежуточного типа, которые наиболее чувствительны к резкому ограничению питьевого режима.

В мышечных волокнах языка вместе с измененными митохондриями и миофибриллами находятся поврежденные органеллы в аксо-мышечных синапсах с признаками как реактивных, так и деструктивных процессов, что указывает на тесную морфофункциональную взаимосвязь между этими структурами.

\section{References}

Amir, O., \& Grinfeld, D. (2011). Articulation rate in childhood and adolescence: Hebrew speakers. Language and Speech, 54(2), 225-240.

Bayline, R. J., Duch, C. C., \& Levine, R. B. (2001). Nerve-muscle interactions regulate motor terminal growth and myoblast distribution during muscle development. Developmental Biology, 231, 348-363.

Bunn, D., Jimoh, F., Wilsher, S., \& Hooper, L. (2014). Effectiveness of extemal factors to reduce the risk of dehydration in older people living in residential care: A systematic review. BMC Health Services Research, 14(Suppl 2), P11.

Choy, V. J. (1986). Isolation and properties of sheep neurohypophysial nerve terminals. Neuropeptides, 7(4), 337-349.

Dana, R. M., \& McCaughey, S. A. (2015). Gustatory responses of the mouse chorda tympani nerve vary based on region of tongue stimulation. Chemical Senses, 40(5), 335-344.

Davidova, L. M., Tkach, G. F., Sikora, V. Z., Kiptenko, L. I., \& Maksimova, O. S. (2016). Dinamika strukturnoji organizaciji jazyka shhuriv za umov vplivu zagal'nogo znevodnennja organizmu [The dynamics of the structural organization of tongue of rats under the influence of general dehydration]. Aktual'ni Problemy suchasnoji Medicyny, 16(4), 8-12 (in Ukranian).

Fritz, M., \& Müller, V. (2007). An intermediate step in the evolution of ATPases F1F0-ATPase from Acetobacterium woodii contains F-type and V-type rotor subunits and is capable of ATP synthesisthe. FEBS Journal, 274(13), 34213428.

Gaffield, M. A., Romberg, C. F., \& Betz, W. J. (2011). Live imaging of bulk endocytosis in frog motor nerve terminals using FM dyes. Journal of Neurophysiology, 106(2), 599-607.

García, M. R., Pearlmutter, B. A., Wellstead, P. E., \& Middleton, R. H. (2013). A slow axon antidromic blockade hypothesis for tremor reduction via deep brain stimulation. PLoS ONE, 8(9), 734-756.

Guttridge, D. C. (2012). Skeletal muscle regeneration. In: Hill, J. (ed.). Muscle. Fundamental Biology and Mechanisms of Disease. Elsevier, 2, 921-933.

Holstege, J. C., \& Kuypers, H. G. J. M. (1987). Brainstem projections to lumbar motoneurons in rat $-\mathrm{I}$. An ultrastructural study using autoradiography and the combination of autoradiography and horseradish peroxidase histochemistry. Neuroscience, 21(2), 345-367.

Hooper, L., \& Bunn, K. (2014). Predictors of dehydration in older people living in UK residential care. European Geriatric Medicine, 5, 202-203.

Hooper, L., Bunn, D., Jimoh, F. O., \& Fairweather-Tait, S. J. (2014). Water-loss dehydration and aging. Mechanisms of Ageing and Development, 136, 50-58.

Hooper, L., Bunn, K., Prado, M., \& Siervo, M. (2014). Assessment of dehydration in older people: Agreement of measured serum osmolality with calculated serum osmolarity equations. European Geriatric Medicine, 5, 80.

Hua, T. E., Yang, T. L., Yang, W. C., Liu, K. J., \& Tang, S. C. (2013). 3-D neurohistology of transparent tongue in health and injury with optical clearing. Frontiers Neuroanatomy, 7, 36-42.

Johansson, G. S., \& Amqvist, H. J. (2006). Insulin and IGF-I action on insulin receptors, IGF-I receptors, and hybrid insulin/IGF-I receptors in vascular smooth muscle cells. AJP: Endocrinology and Metabolism, 291(5), 1124-1130.

Johnstone, A. F. M., Viele, K., \& Cooper, R. L. (2010). Structure/function assessment of synapses at motor nerve terminals. Synapse, 65(4), 287-299.

Knittel, L. M., \& Kent, K. S. (2005). Remodeling of an identified motoneuron during metamorphosis: Hormonal influences on the growth of dendrites and axon terminals in fish. Journal of Neurobiology, 63(2), 106-125.

Kuznetsov, I. A., \& Kuznetsov, A. V. (2014). What tau distribution maximizes fast axonal transport toward the axonal synapse? Mathematical Biosciences, 253, 19-24.

Liu, Z.-J., Shcherbatyy, V., Kayalioglu, M., \& Seifi, A. (2009). Internal kinematics of the tongue in relation to muscle activity and jaw movement in the pig. Journal of Oral Rehabilitation, 36(9), 660-674.

Moore, D. L., \& Goldberg, J. L. (2011). Multiple transcription factor families regulate axon growth and regeneration. Developmental Neurobiology, 71(12), 1186-1211.

Mosendz, T. M., \& Mickan, B. M. (2012). Struktura skeletnogo m’jaza pri termorobochij degidrataciji organizmu [The structure of skeletal muscle during termal dehydration]. Morfologija, 94(1), 150-153 (in Ukranian).

Motoyama, A. A., Watanabe, I. S., Iyomasa, M. M., Silva, M. C. P., Sosthines, M. C. K., Lopes, M. G. O., Guimarães, J. P., \& Kfoury, J. R. (2009). Ultrastructure of motor nerve terminals in the anterior third of wistar rat tongue. Microscopy Research and Technique, 72(6), 464-470.

Mu, L., \& Sanders, I. (2010). Human tongue neuroanatomy: Nerve supply and motor endplates. Clinical Anatomy, 23(7), 777-791.

Mu, L., Sobotka, S., Chen, J., Su, H., Sanders, I., Adler, C. H., Shill, H. A., Caviness, J. N., Samanta, J. E., \& Beach, T. G. (2013). $\alpha$-Synuclein pathology and 
axonal degeneration of the peripheral motor nerves innervating tongue muscles in Parkinson Disease. Journal of Neuropathology and Experimental Neurology, 72(2), 119-129.

Nawaz, S., Schweitzer, J., Jahn, O., \& Werner, H. B. (2013). Molecular evolution of myelin basic protein, an abundant structural myelin component. Glia, 61(8), 1364-1377.

Pathi, B., Kinsey, S. T., Howdeshell, M. E., Priester, C., McNeill, R. S., \& Locke, B. R. (2012). The formation and functional consequences of heterogeneous mitochondrial distributions in skeletal muscle. Journal of Experimental Biology. 215(11), 1871-1883.

Pfeiffer, C. J., Levin, M., \& Lopes, M. A. F. (2000). Ultrastructure of the horse tongue: Further observations on the lingual integumentary architecture. Anatomia, Histologia, Embryologia: Journal of Veterinary Medicine Series C, 29(1), 37-44.

Robin, M., Malbon, A., Ricci, E., McGowan, C., \& Malalana, F. (2013). Reduced tongue tone associated with degeneration of the hypoglossal nerve nucleus in a horse with equine motor neuron disease. Equine Veterinary Education, 28(8), 434-438.

Rothman, J. (2013). Control of membrane fusion in exocytosis. Biophysical Journal, 104(2), 11a.

Simmons, Z. (2016). Changes in muscle and Nerve. Muscle and Nerve, 55(1), 1-2.

Simmons, Z. (2017). The scope of muscle and nerve. Muscle and Nerve, 55(5), 615-616.

Slater, C. R. (2015). The functional organization of motor nerve terminals. Progress in Neurobiology, 134, 55-103.

Slaughter, K., Li, H., \& Sokoloff, A. J. (2006). Neuromuscular organization of the superior longitudinalis muscle in the human tongue 1 . Motor endplate mor- phology and muscle fiber architecture. Cells Tissues Organs, 181(1), 51-64.

Suzuki, E., Aoyama, K., Fukui, T., Nakamura, Y., \& Yamane, A. (2012). The function of platelet-derived growth factor in the differentiation of mouse tongue striated muscle. Orthodontics and Craniofacial Research, 15(1), 39-51.

Tankisi, H., Otto, M., Pugdahl, K., \& Fuglsang-Frederiksen, A. (2013). Spontaneous electromyographic activity of the tongue in amyotrophic lateral sclerosis. Muscle and Nerve, 48(2), 296-298.

Watanabe, I., Guimarães, J. P., Boleta Almeida, S. A. Y., Righeti, M. M., Santos, T. C., Miglino, M. A., \& Kfoury, J. R. (2009). Nerve endings of filliform, fungiform and vallate papillae of dorsal tongue mucosa of White-lipped peccary (Tayassu pecari): Neurohistological observations. Pesquisa Veterinária Brasileira, 29(4), 281-285.

Ye, W., Abu, A. F., \& Liu, Z. J. (2010). Assessment of cell proliferation and muscular structure following surgical tongue volume reduction in pigs (guineia pigs). Cell Proliferation, 43(6), 562-572.

Zciena, A. P., Bolina, C. S., Almeida, S. R. Y., Rici, R. E. G., Oliveira, M. F., Silva, M. C. P., Miglino, M. A., \& Watanabe, I. S. (2013). Structural and ultrastructural features of the agouti tongue (Dasyprocta aguti Linnaeus 1766). Journal of Anatomy, 223,(2), 152-158.

Zghikh, L. N., Vangysel, E., Nonclercq, D., Legrand, A., Blairon, B., Berri, C., Bordeau, T., Rémy, C., Burtéa, C., Montuelle, S. J., \& Bels, V. (2014). Morphology and fibre-type distribution in the tongue of the Pogona vitticeps lizard (Iguania, Agamidae). Journal of Anatomy, 225(4), 377-389.

Zhang, L. F., Moritani, M., Honma, S., Yoshida, A., \& Shigenaga, Y. (2001). Quantitative ultrastructure of slowly adapting lingual afferent terminals in the principal and oral nuclei in the cat. Synapse, 41(2), 96-111. 